\title{
Cystic fibrosis of the pancreas: structural changes in peripheral airways
}

\author{
J OHN R. ESTERLY ${ }^{1}$ AND ELLA H. OPPENHEIMER \\ From the Department of Pathology of the Johns Hopkins University School of Medicine and Hospital, \\ Baltimore, Maryland, U.S.A.
}

\begin{abstract}
Emphysema and bronchiolar obstruction were found in the necropsy specimens from 42 of 84 patients with cystic fibrosis of the pancreas. Significant parenchymal destruction could be demonstrated in only three cases. In contrast, widespread severe dilatation of respiratory bronchioles and alveolar ducts was present in 29 of the older infants and children, and less extensive, moderate dilatation was seen in an additional 13 cases. Eleven patients also had morphological evidence of bronchiolar scarring and stenosis. Because of the chronic pulmonary infection in these patients, it is unlikely that the structural changes in peripheral airways are clinically significant. Nevertheless, this widespread dilatation may be responsible for the physiological and radiographic evidence of emphysema. Furthermore, the lobular dilatation in these young patients may be an antecedent of destructive emphysema in the adult.
\end{abstract}

Pulmonary disease is the most widespread and severe component of cystic fibrosis of the pancreas, and, at present, is chronic, progressive, and the only significant cause of death in patients who survive the neonatal period. Obstruction from abnormal bronchial secretions promotes infection that ultimately results in bronchiectasis. Respiratory obstruction also causes emphysema in many affected patients. But, although widely recognized by paediatricians and radiologists, emphysematous changes in cystic fibrosis have been more difficult for the pathologist to document, and there is no consensus about the type of severity of the morphological findings in the non-inflamed, pulmonary parenchyma.

The present report describes the structural changes in airways distal to the terminal bronchiole in the necropsy specimens of infants and children with cystic fibrosis. The mucous gland alterations in these patients are similar to those in adults with chronic bronchitis. Since destructive emphysema usually accompanies adult chronic bronchitis, the less severe changes described here are of particular interest, and may be useful when considering the pathogenesis of the peripheral lesions in the adult.

\section{OBSERVATIONS}

CASE MATERIAL Descriptions of the gross findings, available tissue, and histological sections from 84

1Present address: Pathology Department, University of Chicago, Chicago, Illinois 60637 cases of cystic fibrosis were reviewed. At least two histological sections were available from allo cases, and there were usually four to eight sections from those over 1 month old. Twenty-oned infants died during the neonatal period, another $\stackrel{\circ}{\circ}$

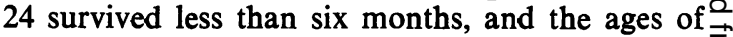
the remaining 39 cases ranged to 15 years. There were 44 boys and 40 girls, and of the 11 children over 8 years six were boys.

PULMONARY FINDINGS At necropsy the lungs of the older infants and children were voluminous and frequently extended outside the opened ${ }_{-}^{\times}$ thorax. The bronchi were characteristically filled 3 with tenacious, purulent secretions, and casts were usually present in many smaller branches. $\frac{3}{3}$ The texture of the cut surface suggested trapped air, and foci of pneumonia and bronchiectasis were readily identified. In several cases cysts or $\frac{7}{0}$ bullae were found, but subpleural and focal scarring was limited to areas of pneumonia. Pneu- $N$ monia was found in two-thirds of the cases, and $N$ bronchitis and/or bronchiolitis in all the patients who survived the neonatal period. Bronchiectasis $\omega$ was present in more than half of the infants over 1 month old, and in all those older than 6 months. Hypertrophy and hyperplasia of the submucosal ${ }_{\mathscr{\infty}}^{\circledR}$ glands were noted in nearly all the older infants. and children.

The chronic pulmonary changes seen in the histological sections included bronchitis and $\stackrel{\odot}{\circ}$ bronchiolitis as well as bronchiectasis. Necrotizing and organizing pneumonia was less common, and 
interstitial fibrosis and muscular hyperplasia were unusual. Bronchiolar-alveolar communications (Lambert's canals) were sometimes seen, and alveolar epithelialization was conspicuous at these points. The detailed pulmonary complications and bacteriological findings in these cases have been reported separately (Esterly and Oppenheimer, 1968).

EXPANSION-FIXED SPECIMENS In five cases, ranging in age from 27 months to 11 years, the lungs had been fixed in expansion, and slices were examined under a dissecting microscope (Heard, 1958, 1960). In numerous foci of the specimen from the oldest case (11 years of age) the cut surface showed the enlarged, similar-sized airways characteristic of minimal to moderate panacinar emphysema, rather than the variation in size of respiratory bronchioles and alveoli that are present in the normal lung. This pattern of panacinar emphysema affected approximately $20 \%$ of the lung. No alterations in the peripheral pulmonary architecture were seen in the noninflamed portions of the other expansion-fixed slices. The lung structure also appeared to be intact in the areas of pneumonia.

PERIPHERAL histological STRUCTURE The distal pulmonary architecture was readily identified, even in the sections from routinely fixed specimens, since the state of expansion in nearly every case resembled that seen in the histological samples from expansion-fixed specimens. The diameter of the respiratory bronchioles and alveolar ducts was increased, and the septa of alveoli lining these passages appeared attenuated and bloodless. Few capillaries were apparent, even in congested tissue.

Histological evidence of bronchiolar obstruction was found in 12 of the 84 cases (see Table). Peripheral bronchiolar scarring associated with significant stenosis was present in 11 of the older patients (Fig. 1); an extensive organizing bronchiolitis (bronchiolitis obliterans) was seen in a 15-month-old infant (Fig. 2). Only isolated, narrowed peripheral bronchioles were counted. Similar small, epithelial-lined airways adjacent to bronchiectatic foci were present in many cases, but these were excluded because, in a single section, they could not always be distinguished from alveolar epithelialization.

Foci of destructive emphysema, in non-inflamed parenchyma, were found in 12 cases, but in only three was an estimated $20 \%$ to $50 \%$ of the pulmonary tissue affected (Figs 3 and 4). The three
T A B L E

PERIPHERAL PULMONARY FINDINGS AT NECROPSY IN CASES OF CYSTIC FIBROSIS

\begin{tabular}{|c|c|c|c|c|c|}
\hline & & \multicolumn{4}{|c|}{ Age at Death } \\
\hline & & $\begin{array}{l}1-30 \\
\text { days }\end{array}$ & $\stackrel{1-6}{\text { months }}$ & $\stackrel{>6}{\text { months }}$ & $\begin{array}{c}\text { All } \\
\text { Cases }\end{array}$ \\
\hline $\begin{array}{l}\text { Total cases . } \\
\text { Bronchiolar stenosis } \\
\text { Lobular dilatation }\end{array}$ & $\begin{array}{l}\cdots \\
\cdots\end{array}$ & $\begin{array}{r}21 \\
0\end{array}$ & $\begin{array}{r}24 \\
0\end{array}$ & $\begin{array}{l}39 \\
12^{1}\end{array}$ & $\begin{array}{l}84 \\
12\end{array}$ \\
\hline $\begin{array}{cc}\text { Moderate } & \ldots\end{array}$ & $\begin{array}{l}\ddot{*} \\
\ddot{*}\end{array}$ & $\begin{array}{l}\mathbf{0} \\
\mathbf{0} \\
\mathbf{0}\end{array}$ & $\begin{array}{l}7 \\
7 \\
0\end{array}$ & $\begin{array}{r}6 \\
22 \\
3\end{array}$ & $\begin{array}{r}13 \\
29 \\
3\end{array}$ \\
\hline
\end{tabular}

1 Includes one case of organizing bronchiolitis.

patients were 8,11 , and 12 years of age. In the remaining nine cases over $95 \%$ of the noninflamed lung was not involved, and in many the only lesions were isolated cyst-like spaces adjacent to foci of bronchiectasis. The distribution of the emphysema could not be determined with certainty in this small sample, but it appeared to be either random or paraseptal. Respiratory bronchioles were not involved, and there was no pigment deposition.

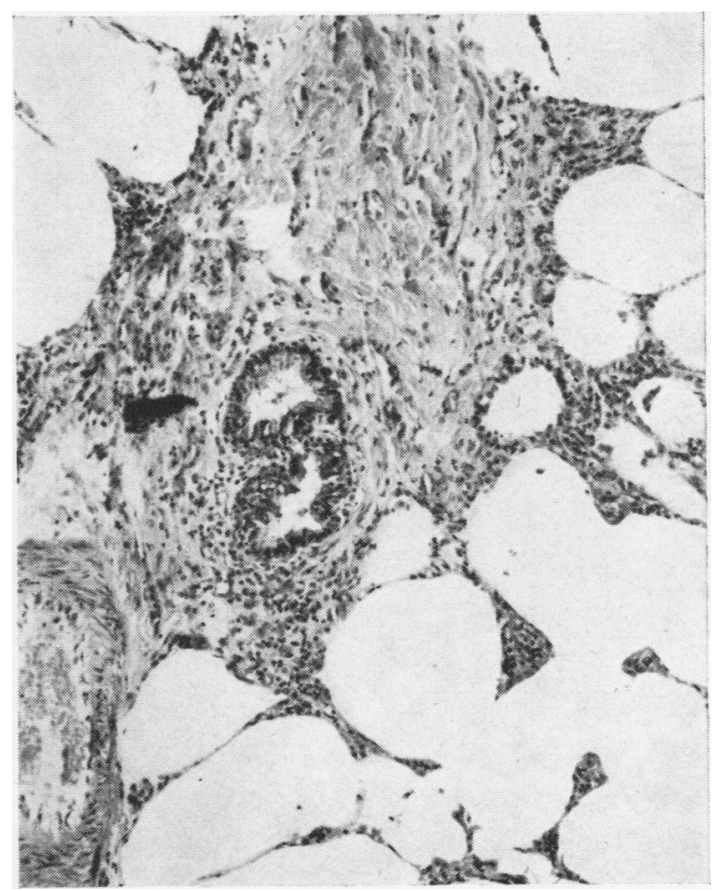

FIG. 1. An area of stenosis in a terminal bronchiole embedded in a focus of fibrosis from an 11-year-old girl with brcnchiectasis. The bronchiole has been sectioned near a point of bifurcation, yet the combined diameter is no larger than that of the surrounding alveoli. $H$. and $E . \times 95$. 


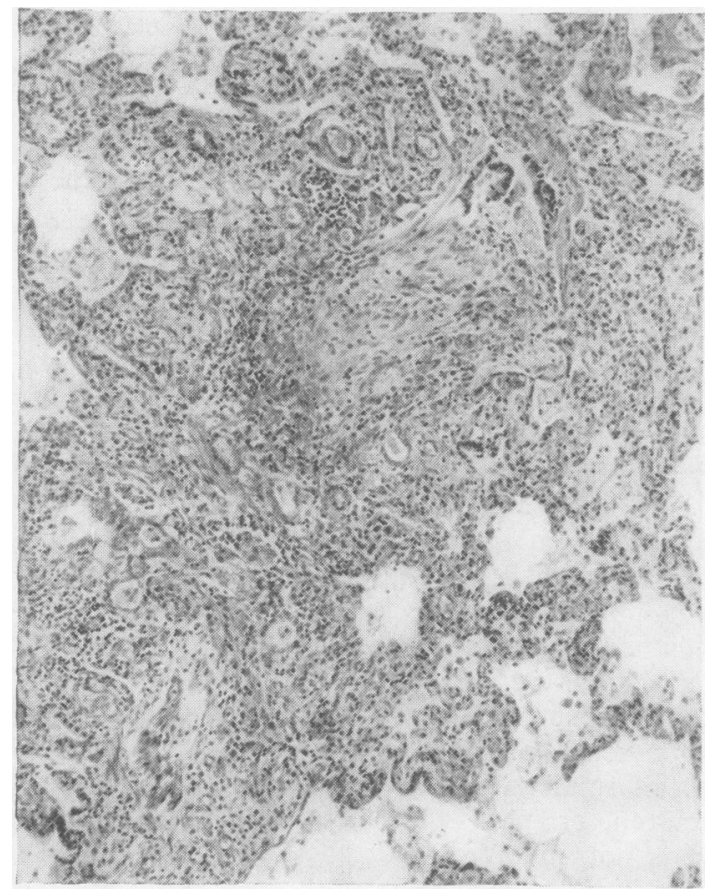

FIG. 2. Intraluminal organization (bronchiolitis obliterans) was found in only one case. Normal bronchiolar epithelium remains at the upper edge of the lumen. H. and E. $\times 95$.

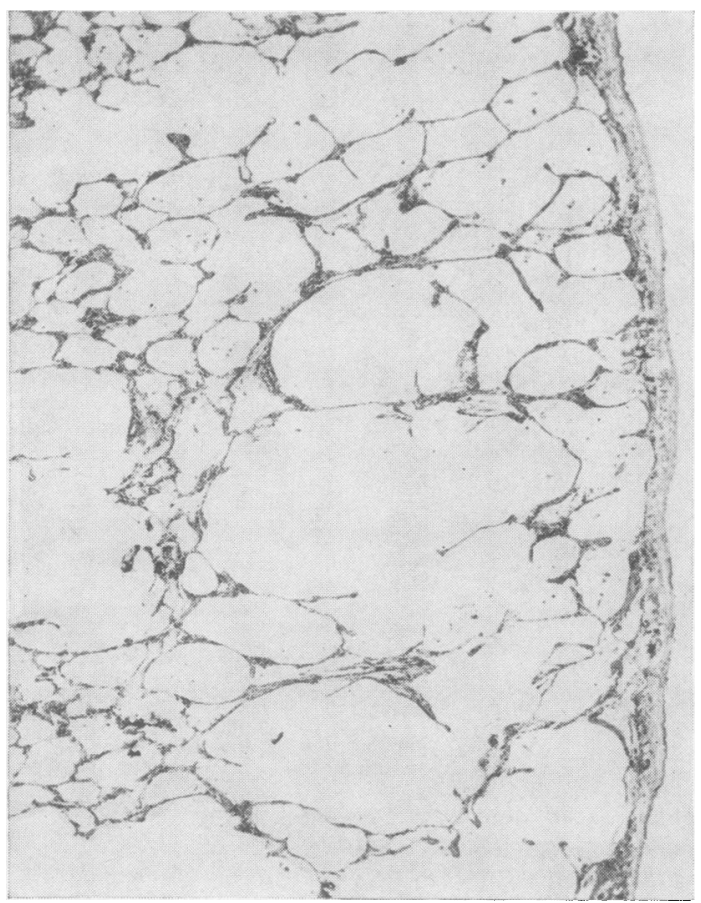

FIG. 3. Destructive panacinar emphysema was also found in the case illustrated in Fig. 1. H. and E. $\times 22$.

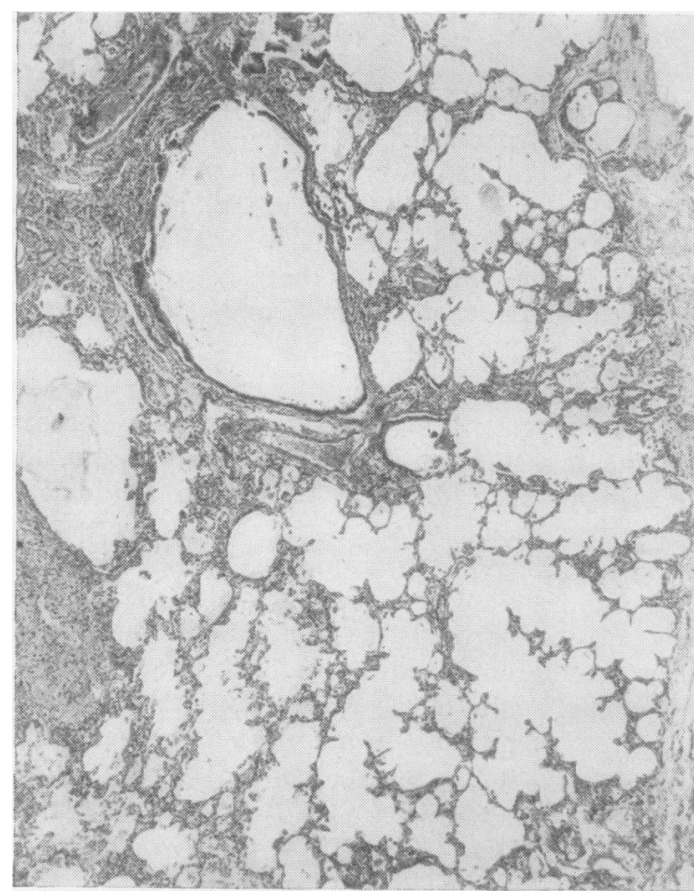

FIG. 4. An area of subpleural bronchiectasis in a 3-month old infant is surrounded by distension of peripheral airways without structural alteration. H. and E. $\times 22$.

The cases with destructive lesions included all $\vec{\circ}$ the older patients and two infants, $2 \frac{1}{2}$ and 83 months of age. Chronic bronchitis and bronchiectasis were present in each, and extensive peribronchial and bronchiolar scarring and stenosis were found in six.

Dilatation emphysema was both more frequent $\tilde{x}$ and more widespread within the lung. Although $\frac{0}{3}$ air trapping with full expansion or even distension of respiratory bronchioles, alveolar ducts, $O$ and acini was a common finding (Fig. 4), the dilatation seen on close inspection of the pattern 음 of the secondary lobule was a more subtle, but $>$ none the less striking, alteration. The height of alveolar septa along respiratory bronchioles and N alveolar ducts and within acini was reduced and the normal cup-shaped appearance of the alveoli $N$ was lost. In the most extreme cases the exact ${ }_{\omega}^{N}$ identification of septa was difficult (Figs 5 and 6). 우 The diameter of the respiratory bronchioles ando

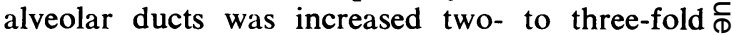
as a result of the saucer-shaped lining alveoli. ?

The cases were arbitrarily grouped according 0 to the severity and extent of the dilatation. Twenty-nine cases showed severe involvement: alveolar septa of less than half the normal height $\stackrel{\mathbb{Q}}{\stackrel{Q}{\circ}}$ in more than one-third of the total area. Minimal $\overline{0}$ to moderate dilatation, or more limited involve- 


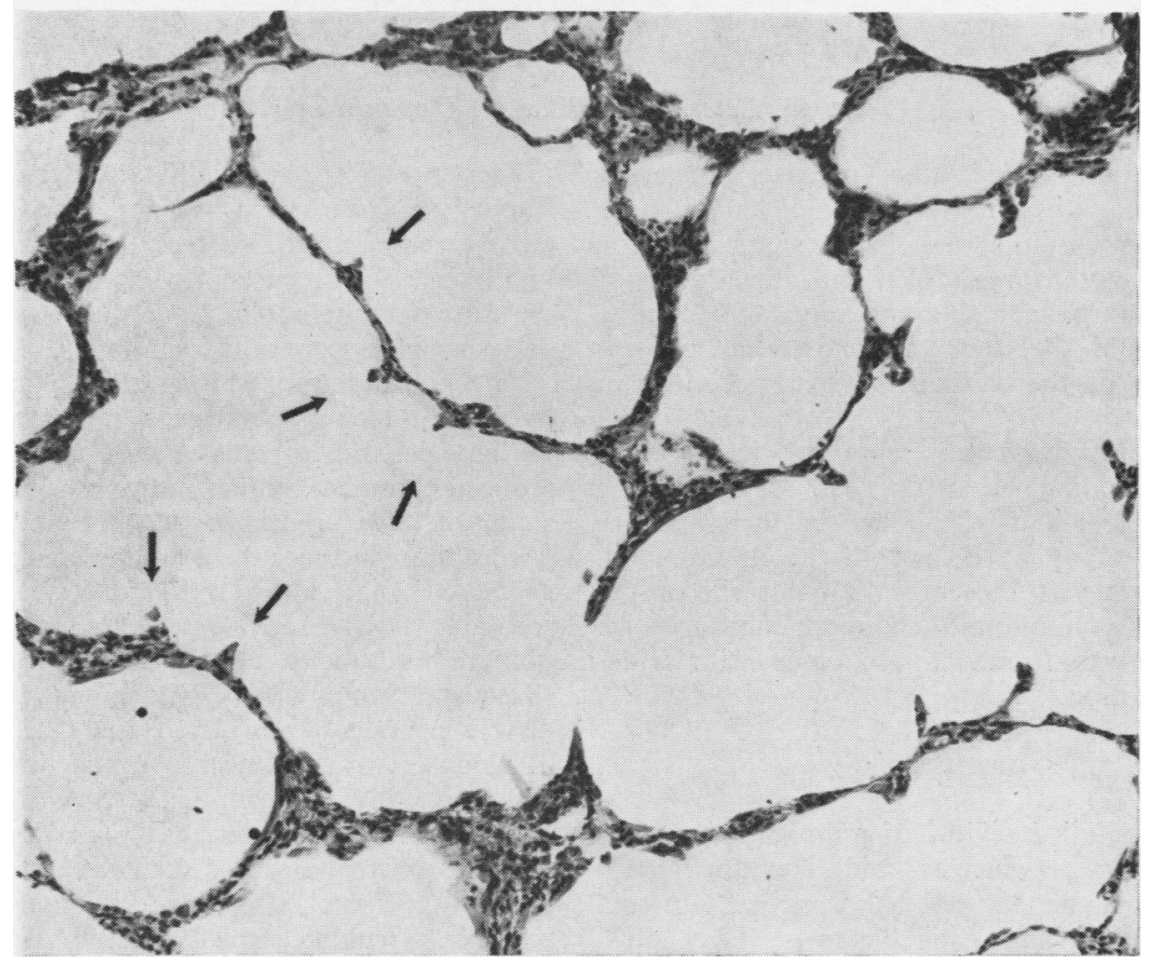

FIG. 5. Photomicrograph of a respiratory bronchiole and adjacent alveolar duct from a 3-year-old child with bronchiectasis shows the reduced height in the septa dividing the lining alveoli. $H$. and $E . \times 155$.

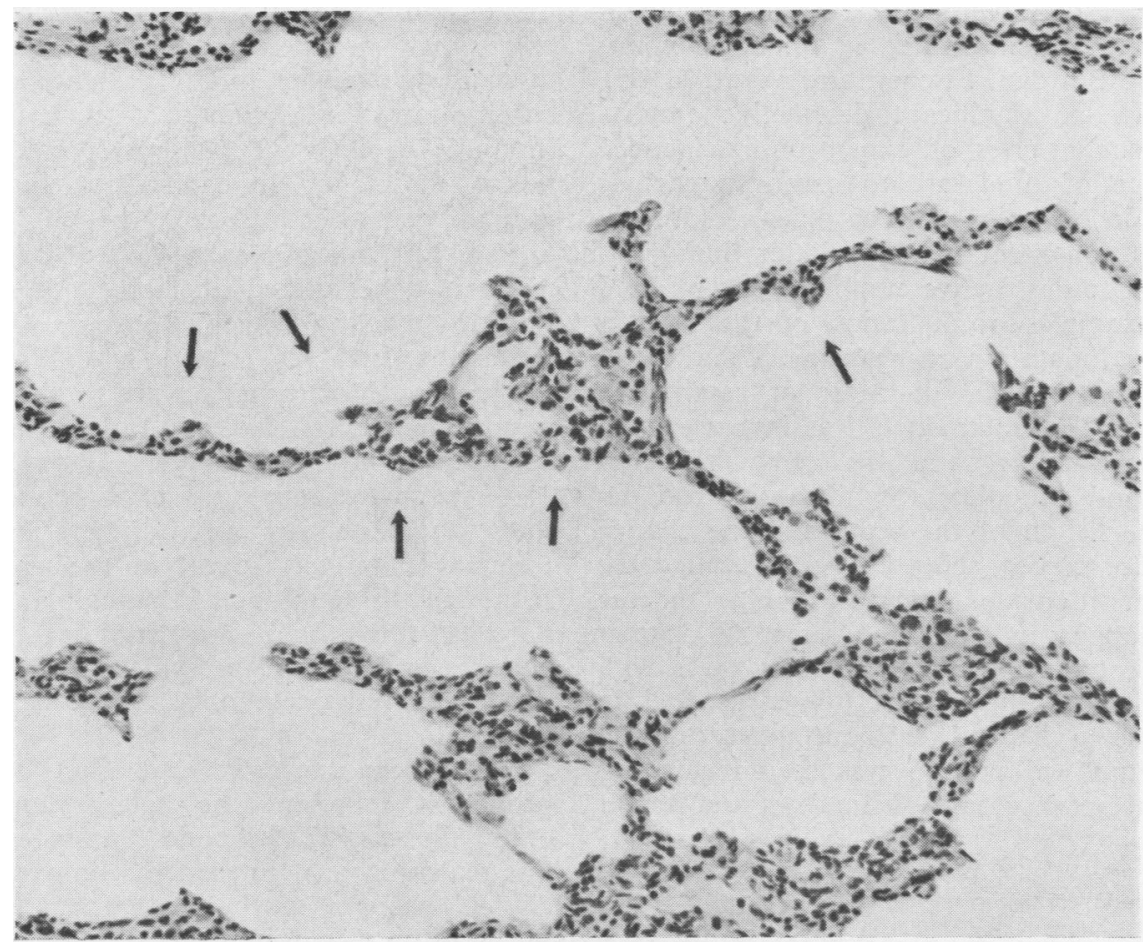

FIG. 6. A similar section from a 2-month-old infant with interstitial pneumonia shows virtual disappearance of alveolar septa. $H$. and $E . \times 155$.

The photomicrographs were taken by Raymond Lund. 
ment, was found in 13 other patients. ${ }^{2}$ In seven of the cases with extensive histological changes the alteration was so severe that in some areas the histological pattern resembled the appearance of a very regular panacinar emphysema. No definite changes could be detected, however, on reexamination of the available gross specimens in these cases.

The most severe changes were seen in the older patients, including all with foci of destructive emphysema, but half of the cases with less severe or limited lesions were less than 6 months old. Bronchiectasis was present in all but six of the infants with minimal changes; bronchiolar obstruction was found in six cases with widespread dilatation.

\section{DISCUSSION}

In the first detailed review of pulmonary changes in cystic fibrosis Zuelzer and Newton (1949) found emphysema as well as bronchial obstruction, bronchitis, and bronchiectasis. They illustrated scarring and cyst-like spaces and described changes compatible with air trapping and alveolar dilatation. They concluded that bronchial obstruction rather than the sequelae of infection caused the emphysema, since it was found in three infants with no evidence of infection. Similar changes were described and illustrated in Bodian's monograph (1952). Bowden, Fischer, and Wyatt (1965), however, saw no significant destructive emphysema in a small series of expansion-fixed cases. The presence of moderate to severe panacinar emphysema in only three of the older children in this series is consistent with the latter finding.

In contrast to destructive emphysema, we found numerous examples of dilatation of the respiratory airways (dilatation emphysema, Ciba Guest Symposium, 1959). The diameter of respiratory bronchioles and alveolar ducts was increased, the alveoli were shallow, and the septa appeared attenuated and bloodless. Significantly, the decrease in the height of the septa and the change from 'cup' to 'saucer' shaped alveoli recalled the earlier observations of Hartroft (1945) on the histological appearance of emphysema. All degrees of severity could be identified, but in cases with the most changes there were numerous foci in which the septa had virtually disappeared, and a greatly simplified pattern was seen instead of the usual lacework of alveoli in rows and acinar groups.

2 Six neonatal cases with meconium ileus and exaggerated atelectasis (Swiss cheese dilatation of respiratory bronchioles) were excluded from this group.
This non-destructive dilatation could be dis- $\stackrel{\overrightarrow{\bar{S}}}{\stackrel{9}{9}}$ tinguished from air trapping, and it was sufficiently severe to be interpreted as an alteration $\frac{\bar{\sigma}}{\bar{m}}$ in the peripheral parenchymal structure in 42 of $\underset{\nabla}{\vec{D}}$ the 84 cases, including 28 of the 39 patients who had survived six months or longer.

The end result of this alteration is a decrease $\vec{\circ}$ in the alveolar population. The pathogenesis of the changes, however, is uncertain. Prior to birth, $\vec{\omega}$ reduced thoracic volume results in decreased division of the pulmonary conducting airways $\vec{x}$ (Areechon and Reid, 1963), but it has been $\underset{\omega}{N}$ suggested that after birth airways obstruction 0 secondary to bronchiectasis and bronchiolitis obliterans results in a decreased number of alveoli

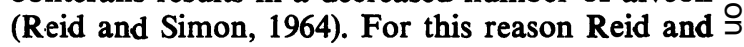
de Haller (1964) postulated that the appearance $\vec{T}$ of alveolar simplification in cystic fibrosis reflects $Z$ a relative alveolar hypoplasia. A similar histo- $\Phi$ logical picture, however, has been described with $\frac{\Im}{\sigma}$ chronic overexpansion, such as occurs in the $\stackrel{\mathbb{Q}}{\stackrel{1}{-}}$ remaining lung after experimental pneumon- $\vec{\theta}$ ectomy (Rienhoff, Reichert, and Heuer, 1935). Therefore it seems that air trapping may be an important factor in the dilatation in these patients, but until alveolar counts are made (Emery and Mithal, 1960; Dunnill, 1962), the contribution of hypoplasia cannot be determined.

The significance of the structural changes in the $\stackrel{\mathbb{Q}}{\varrho}$ respiratory bronchioles and alveolar ducts is $\overrightarrow{0}$ difficult to evaluate in the presence of universal 3 chronic infection. Although it seems unlikely that this dilatation is of clinical significance, these? lesions may offer an explanation for the radiographic emphysema seen in patients with cystic 응 fibrosis (di Sant 'Agnese, 1953). It may also con- $x$ tribute to the altered physiology of chronic air-응 ways obstruction (Beier, Renzetti, Mitchell, and Watanabe, 1966).

The bronchiolar changes are probably the most important irreversible structural cause of airways 9 obstruction in cystic fibrosis (Thurlbeck, 1967), D and systematic enumeration of bronchioles may? show that stenosis and obliteration is more N frequent than was found in the present study. Although the aetiology of bronchiolar stenosis has not been discussed in our series, we think it may have resulted from the widespread bronchiolitis and interstitial pneumonia with which it is asso-e ciated.

It has been suggested that adults with chronic? bronchitis represent the heterozygous form of cystic fibrosis (Karlish and Tárnoky, 1961). For this reason it is of interest to compare the paren- $\stackrel{\mathbb{Q}}{\overparen{D}}$ chymal changes in the two groups. Bronchiolar $\stackrel{\mathbb{Q}}{\alpha}$ obstruction was found in a third of the oldero 
infants and children, and is probably more frequent, but it is an uncommon finding in adult chronic pulmonary disease (Esterly and Heard, 1965). Destructive emphysema may, on occasion, be minimal in the adult with chronic airways obstruction (Simpson, Heard, and Laws, 1963 ; Hentel, Longfield, Vincent, Filley, and Mitchell, 1963), just as has been found in the present cases, but in the majority of patients with obstructive pulmonary disease, morphological evidence of both emphysema and chronic bronchitis can be found, although either may predominate (Thurlbeck, 1963 ; Mitchell, Vincent, Ryan, and Filley, 1964 ; Burrows, Fletcher, Heard, Jones, and Wootliff, 1966).

Destructive emphysema is almost certainly an unimportant factor in cystic fibrosis, but its frequency and severity in the increasing number of adult survivors has not been studied. Although the actual loss of area for gas exchange may be greater lobular dilatation is probably also of limited significance. Its association with age and the presence of destructive emphysema, however, suggests that this dilatation, especially when severe, may be irreversible, and an antecedent of destructive panacinar emphysema.

This work was supported in part by U.S.P.H.S., NIGMS Training Grant 5-TOI-GM-00415.

\section{REFERENCES}

Areechon, W., and Reid, L. (1963). Hypoplasia of lung with congenital diaphragmatic hernia. Brit. med. J., 1, 230.

Beier, F. R., Renzetti, A. D., Mitchell, M., and Watanabe, S. (1966). Pulmonary pathophysiology in cystic fibrosis. Amer. Rev. resp. Dis., 94, 430 .
Bodian, M. (1952). Fibrocystic Disease of the Pancreas. Heinemann, London.

Bowden, D. H., Fischer, V. W., and Wyatt, J. P. (1965). Cor pulmonale in cystic fibrosis. Amer. J. Med., 38, 226.

Burrows, B., Fletcher, C. M., Heard, B. E., Jones, N. L., and Wootliff, J. S. (1966). The emphysematous and bronchial types of chronic airways obstruction. Lancet, $1,830$.

Ciba Guest Symposium (1959). Terminology, definitions, and classification of chronic pulmonary emphysema and related conditions. Thorax, 14, 286.

di Sant 'Agnese, P. A. (1953). Bronchial obstruction with lobar atelectasis and emphysema in cystic fibrosis of the pancreas. Pediatrics, 12, 178.

Dunnill, M. S. (1962). Postnatal gro' th ol the lung. Thorax, 17, 329.

Emery, J. L., anu Mithal, A. (1960). The number of alveoli in the terminal respiratory unit of man during late intrauterine life and childhood. Arch. Dis. Childh., 35, 544.

Esterly, J. R., and Heard, B. E. (1965). Multiple bronchiolar stenoses in a patient with generalized airways obstruction. Thorax, 20, 309.

- and Oppenueimer, E. H. (1968). Observations in cystic fibrosis of the pancreas. III. Pulmonary lesions. Johns Hopk. med. J., 122 (in the press).

Hartroft, W. S. (1945). The microscopic diagnosis of pulmonary emphysema. Amer. J. Path., 21, 889.

Heard, B. E. (1958). A pathological study of emphysema of the lungs with chronic bronchitis. Thorax, 13, 136.

(1960). Pathology of pulmonary emphysema. Amer. Rev. resp. Dis., 82, 792.

Hentel, W., Longfield, A. N., Vincent, T. N., Filley, G. F., and Mitchell, R. S. (1963). Fatal chronic bronchitis. Ibid., 87, 216.

Karlish, A. J., and Tárnoky, A. L. (1961). Mucoviscidosis and chronic lung disease. Proc. roy. Soc. Med., 54, 980.

Mitchell, R. S., Vincent, T. N., Ryan, S., and Filley, G. F. (1964) Chronic obstructive bronchopulmonary disease. IV. The clinical and physiological differentiation of chronic bronchitis and emphysema. Amer. J. med. Sci., 247, 513.

Reid, L., and de Haller, R. (1964). Lung changes in cystic fibrosis, in Cystic Fibrosis, ed. Hubble, D., p. 21. The Chest and Heart Association, London.

- and Simon, G. (1964). The role of alveolar hypoplasia in some types of emphysema. Brit. J. Dis. Chest, 58, 158.

Rienhoff, W. F., Jr., Reichert, F. L., and Heuer, G. J. (1935). Compensatory changes in the remaining lung following total pneumonectomy. Bull. Johns Hopk. Hosp., 57, 373.

Simpson, T., Heard, B., and Laws, J. W. (1963). Severe irreversible airways obstruction without emphysema. Thorax, 18, 361 .

Thurlbeck, W. M. (1963). Pulmonary emphysema. Amer. J. med. Sci., 246, 332.

(1967). Personal communication.

Zuelzer, W. W., and Newton, W. A. (1949). The pathogenesis of fibrocystic disease of the pancreas; a study of 36 cases with special references to the pulmonary lesions. Pediatrics, 4, 53. 